Supporting Information

\title{
A Flash Chemistry Approach to Organometallic C-Glycosylation for the Synthesis of Remdesivir
}

\author{
Timo von Keutz, ${ }^{\dagger, \neq}$ Jason D. Williams, ${ }^{*,+\neq}$ C. Oliver Kappe ${ }^{*,+, \neq}$
}




\section{Contents}

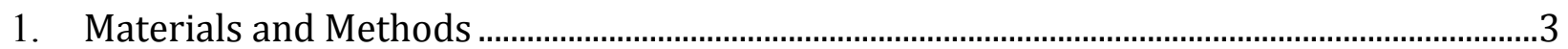

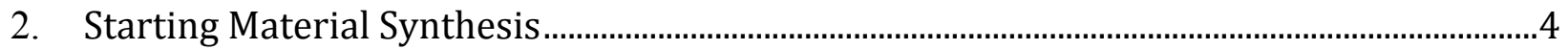

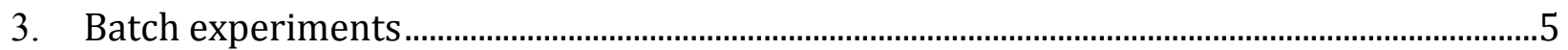

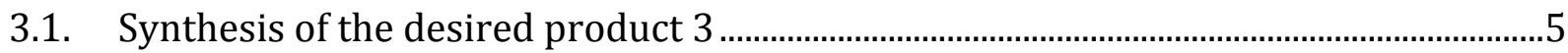

3.2. Combination of Grignard (for deprotonation) and $n$-BuLi (for Li-Br exchange) ........6

3.3. $\quad C$-glycosylation process in the absence of silyl-protecting groups.................................

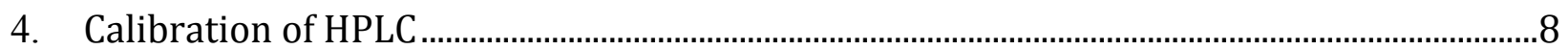

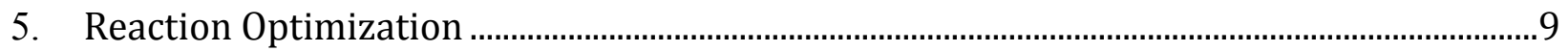

5.1. Continuous flow process in the absence of a silyl-protecting group ............................12

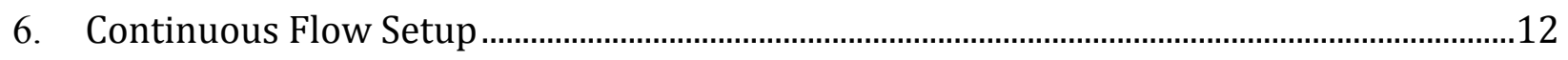

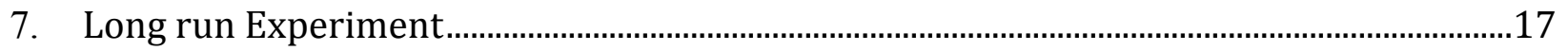

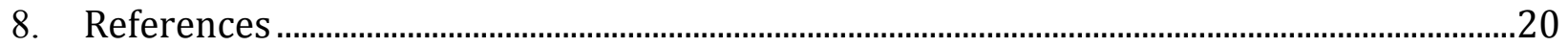

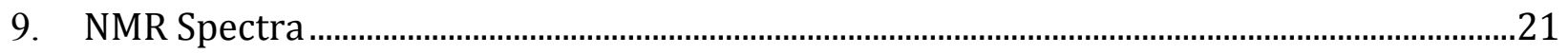




\section{Materials and Methods}

2,3,5-Tri-O-benzyl-D-ribonolactone was purchased from Carbosynth Biosynth (Catalog\# MT05275). Pyrrolotriazine 7 was purchased from Hunan Huateng Pharmaceutical Co. (Catalog\# 80083057, purity $\geq 98 \%$ ). $n$-Butyllithium was purchased as a solution in hexanes from Acros (Catalog\# 181271000, 1.6 M concentration in hexanes). $N, N$-Diisopropylamine was purchased from Sigma Aldrich (Catalog\# 471224, purity $299.5 \%$ ). 1,2Bis(chlorodimethylsilyl)ethane (BCDSE) was purchased from Fluorochem (Catalog\# S01325, purity 95\%). Tetrahydrofuran was purchased from Acros (Catalog\# 348450010, 99.5\% purity, extra dry over molecular sieves, stabilized, AcroSeal). All reagents were used as purchased, without further purification. Unless stated, all solutions were made up under an inert atmosphere, using dry solvent and argon-purged glassware and argon balloons for manipulation.

NMR spectra were recorded on Bruker $300 \mathrm{MHz}$ spectrometer $\left({ }^{1} \mathrm{H}: 300 \mathrm{MHz},{ }^{13} \mathrm{C}: 75 \mathrm{MHz}\right)$. The chemical shifts $(\delta)$ for ${ }^{1} \mathrm{H}$ and ${ }^{13} \mathrm{C}$ are given in ppm relative to residual signals of the solvent (DMSO- $d_{6}$ or $\mathrm{CDCl}_{3}$ ). Coupling constants are given in Hertz $(\mathrm{Hz})$. The following abbreviations are used to indicate the multiplicity: s, singlet; $d$, doublet; $t$, triplet; q, quartet; dd, doublet of doublets; m, multiplet.

Chromatographic purification was accomplished on a Biotage Isolera automated flash chromatography system using cartridges packed with KP-SIL, $60 \AA$ (32-63 $\mu \mathrm{m}$ particle size).

For thin layer chromatography (TLC) analysis, Merck pre-coated TLC plates (silica gel 60 GF254, $0.25 \mathrm{~mm}$ ) were employed, using UV light as the visualizing agent (254 $\mathrm{nm}$ ).

Organic solutions were concentrated under reduced pressure on a Heidolph rotatory evaporator.

Analytical HPLC (Shimadzu LC20) analysis was carried out on a C18 reversed-phase analytical column (150 $\mathrm{mm} \times 4.6 \mathrm{~mm}$, particle size $5 \mu \mathrm{m})$ at $37^{\circ} \mathrm{C}$ using mobile phases A $(90: 10 \mathrm{v} / \mathrm{v}$ water/acetonitrile $+0.1 \% \mathrm{TFA})$ and $\mathrm{B}(\mathrm{MeCN}+0.1 \% \mathrm{TFA})$ at a flow rate of 1.5 $\mathrm{mL} / \mathrm{min}$. The following gradient was applied: start at $3 \%$ solvent $\mathrm{B}$, increase to $100 \%$ solvent B until 15 min. 


\section{Starting Material Synthesis}

\section{Synthesis of 4-amino-7- bromopyrrolo[2,1-f][1,2,4]triazine $1^{1}$}

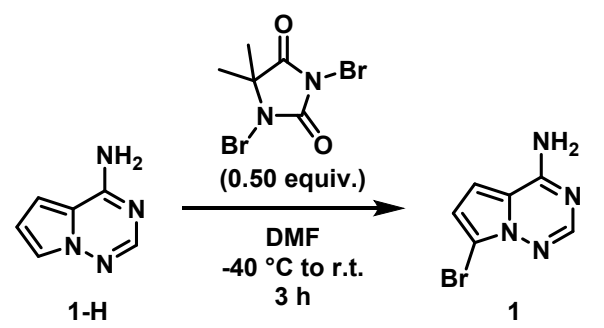

To a solution of 4-aminopyrrolo[2,l-f][1,2,4]-triazine (1-H, 31.8 g, 237.0 mmol, 1.00 equiv.) in $N, N$-dimethylformamide $(300 \mathrm{~mL})$ was added 1,3-dibromo-5,5-dimethylhydantoin (33.9 g, $118.5 \mathrm{mmol}, 0.50$ equiv.) in portions at $-40{ }^{\circ} \mathrm{C}$. Upon complete addition, the reaction mixture was slowly warmed to $0{ }^{\circ} \mathrm{C}$ and $\mathrm{NaOH}_{\text {aq. }}(1.0 \mathrm{M}, 2.5 \mathrm{~L})$ was added to the reaction mixture. The resulting slurry was agitated at room temperature for about $3 \mathrm{~h}$. The solids were filtered, rinsed with water $(500 \mathrm{~mL})$ and dried at $50{ }^{\circ} \mathrm{C}$ under vacuum for 2 days to yield 4-amino-7-bromopyrrolo[2,l-f][l,2,4]triazine (1, 47.1 g, $221 \mathrm{mmol}, 93 \%$ yield) as a beige powder.

${ }^{1} \mathrm{H}-\mathrm{NMR}\left(300 \mathrm{MHz}, \mathrm{DMSO}-d_{6}\right) \delta 7.92(\mathrm{~s}, 1 \mathrm{H}), 7.88(\mathrm{~s}, 2 \mathrm{H}), 6.99(\mathrm{~d}, J=4.5 \mathrm{~Hz}, 1 \mathrm{H}), 6.77$ (d, $J=4.5 \mathrm{~Hz}, 1 \mathrm{H}) .{ }^{13} \mathrm{C}-\mathrm{NMR}\left(75 \mathrm{MHz}\right.$, DMSO-d ${ }_{6} \delta 155.7,149.3,116.3,112.8,103.1,100.0$. Analytical data matches that reported in the literature. ${ }^{1}$ 


\section{Batch experiments}

\subsection{Synthesis of the desired product 3}
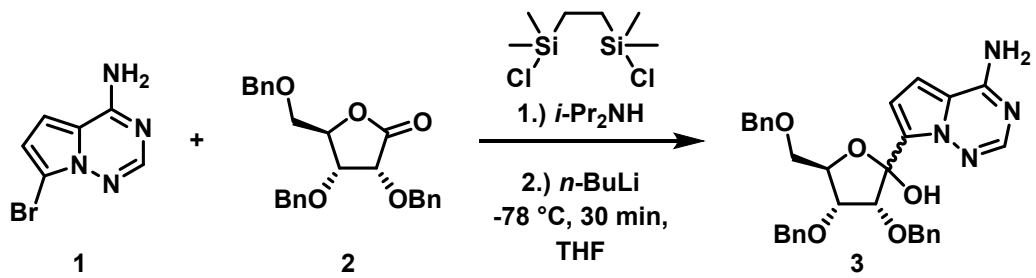

To a solution of 7-bromopyrrolo[2,1-f][1,2,4]triazin-4-amine (1, $213 \mathrm{mg}, 1.00 \mathrm{mmol}$, 1.00 equiv) and biphenyl (internal standard, $30.8 \mathrm{mg}, 0.20 \mathrm{mmol}, 0.20$ equiv.) in dry THF $(10 \mathrm{~mL})$ was added a solution of 1,2-bis(chlorodimethylsilyl)ethane (BCDSE, $1.0 \mathrm{M}$ in dry THF, $1.0 \mathrm{~mL}, 1.00 \mathrm{mmol}, 1.00$ equiv) at room temperature. After 10 min the slurry was cooled to $-40^{\circ} \mathrm{C}$ and DIPA (101 mg, $1.00 \mathrm{mmol}, 1.00$ equiv) was added, followed by the dropwise addition of $n$-BuLi (1.6 M in hexanes, $2.7 \mathrm{~mL}, 4.30 \mathrm{mmol}, 4.30$ equiv) over $15 \mathrm{~min}$ [samples were taken after 1.0, 2.0, 3.0 and 4.3 equiv. of $n$-BuLi]. 2,3,5-Tri-O-benzyl-D-ribono1,4-lactone (2, $1.0 \mathrm{M}$ in dry THF, $2.0 \mathrm{~mL}, 2.00 \mathrm{mmol}, 2.00$ equiv) was added dropwise over $5 \mathrm{~min}$. The reaction mixture was slowly warmed to $0{ }^{\circ} \mathrm{C}$, quenched with $\mathrm{NH}_{4} \mathrm{Cl}_{\text {aq. }}(10 \mathrm{~mL})$ and extracted with $\mathrm{Et}_{2} \mathrm{O}(3 \times 10 \mathrm{~mL})$. The combined organic layers were dried over $\mathrm{Na}_{2} \mathrm{SO}_{4}$ and the volatiles were removed under reduced pressure at room temperature (caution: heating to $40^{\circ} \mathrm{C}$ leads to degradation of the product). The crude product was purified using flash column chromatography (gradient 10\% $\rightarrow 100 \%$ EtOAc in petrol ether) to yield the desired product 3. ${ }^{1} \mathrm{H}$ NMR $\left(300 \mathrm{MHz}\right.$, DMSO- $\left.d_{6}\right) \delta 8.18(\mathrm{~s}, 2 \mathrm{H}), 8.07(\mathrm{~s}, 1 \mathrm{H}), 7.42(\mathrm{~d}, J=4.8 \mathrm{~Hz}, 1 \mathrm{H})$, $7.38-7.25(\mathrm{~m}, 10 \mathrm{H}), 7.19-7.14(\mathrm{~m}, 3 \mathrm{H}), 7.08-7.03(\mathrm{~m}, 3 \mathrm{H}), 5.48(\mathrm{~d}, J=5.7 \mathrm{~Hz}, 1 \mathrm{H}), 5.18(\mathrm{~d}$, $J=5.1 \mathrm{~Hz}, 1 \mathrm{H}), 4.68-4.47(\mathrm{~m}, 6 \mathrm{H}), 4.12(\mathrm{~s}, 1 \mathrm{H}), 4.08-3.99(\mathrm{~m}, 1 \mathrm{H}), 3.77(\mathrm{dd}, J=10.0,3.3 \mathrm{~Hz}$, 1H), 3.56 (dd, $J=10.0,6.2 \mathrm{~Hz}, 1 \mathrm{H}$ ). ${ }^{13} \mathrm{C}$ NMR (75 MHz, DMSO) $\delta$ 188.5, 156.4, 149.5, 139.1, 138.9, 138.6, 129.2, 128.7, 128.7, 128.6, 128.3, 128.2, 128.2, 128.1, 128.0, 127.9, 127.7, 127.7, 127.6, 127.5, 119.1, 118.0, 103.7, 102.8, 101.9, 82.4, 81.4, 73.0, 72.8, 72.2, 71.9, 69.9. Analytical data matches that reported in the literature. ${ }^{2}$ 
Table S1. Reaction progress depending on the amount of $n$-BuLi added to the reaction mixture.

\begin{tabular}{cccccc}
\hline Entry & BuLi equiv. & $\mathbf{1}^{\mathrm{a}}$ & $\mathbf{1 - H}^{\mathrm{b}}$ & $\mathbf{3}^{\mathrm{b}}$ & $\mathbf{8}^{\mathrm{a}}$ \\
\hline 1 & 1.00 & 64 & 34 & - & 0 \\
2 & 2.00 & 35 & 62 & - & 0 \\
3 & 3.00 & $<5$ & 74 & - & 12 \\
4 & 4.30 & $<5$ & 80 & - & 12 \\
$5^{\mathrm{c}}$ & 4.30 & $<5$ & 12 & 66 & 12 \\
\hline
\end{tabular}

Samples were taken from the reaction mixture and quenched with $\mathrm{NH}_{4} \mathrm{Cl}_{\text {aq. }}{ }^{\text {a }} \mathrm{HPLC}$ area\%. ${ }^{\mathrm{b}} \mathrm{HPLC}$ yield versus internal standard. ${ }^{\mathrm{c}}$ After the addition of ribonolactone 2 (2.00 equiv).

\subsection{Combination of Grignard (for deprotonation) and $n$-BuLi (for Li-Br exchange)}
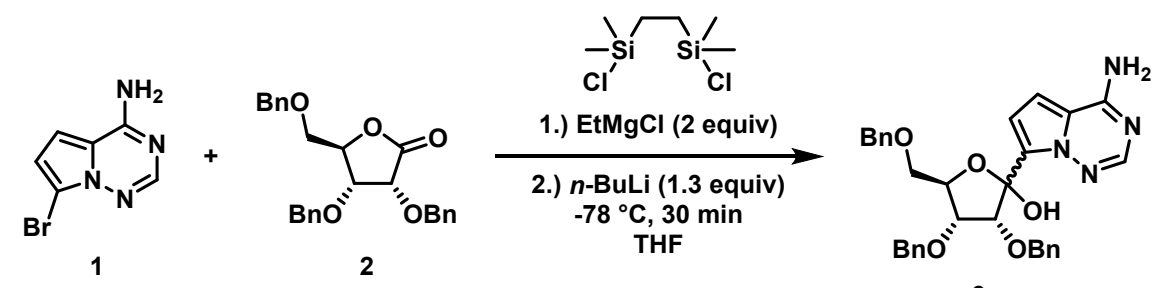

To a solution of 7-bromopyrrolo[2,1-f][1,2,4]triazin-4-amine (1, $213 \mathrm{mg}, 1.00 \mathrm{mmol}$, 1.00 equiv) and biphenyl (internal standard, $30.8 \mathrm{mg}, 0.20 \mathrm{mmol}, 0.20$ equiv.) in dry THF $(10 \mathrm{~mL})$ was added a solution of 1,2-bis(chlorodimethylsilyl)ethane (BCDSE, 1.0 M in dry THF, $1.0 \mathrm{~mL}, 1.00 \mathrm{mmol}, 1.00$ equiv) at room temperature. After $10 \mathrm{~min}$ the slurry was cooled to $-80^{\circ} \mathrm{C}$ and $\mathrm{EtMgCl}(2.0 \mathrm{M}$ in THF, $1.0 \mathrm{~mL}, 2.00 \mathrm{mmol}, 2.00$ equiv) was added dropwise. Afterwards, $n$-BuLi (1.6 M in hexanes, $0.81 \mathrm{~mL}, 1.30 \mathrm{mmol}, 1.30$ equiv) was added dropwise over $5 \mathrm{~min}$, followed by the dropwise addition of 2,3,5-tri- $O$-benzyl-D-ribono-1,4lactone (2,1.0 M in dry THF, $2.0 \mathrm{~mL}, 2.00 \mathrm{mmol}, 2.00$ equiv) over $5 \mathrm{~min}$. The reaction mixture was slowly warmed to $0{ }^{\circ} \mathrm{C}$, quenched with $\mathrm{NH}_{4} \mathrm{Cl}_{\text {aq. }}(10 \mathrm{~mL})$ and subjected to HPLC analysis. The crude mixture contained $36 \%$ yield of the desired product 3 , using biphenyl as internal standard. 


\section{3. $C$-glycosylation process in the absence of silyl-protecting groups}

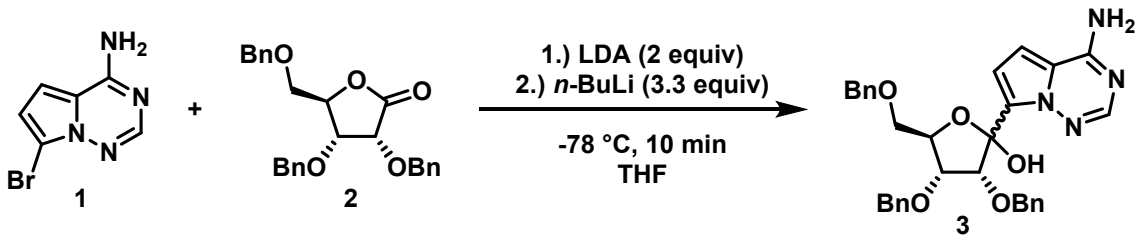

To a solution of 7-bromopyrrolo[2,1-f][1,2,4]triazin-4-amine (1, $213 \mathrm{mg}, 1.00 \mathrm{mmol}$, 1.00 equiv) and biphenyl (internal standard, $30.8 \mathrm{mg}, 0.20 \mathrm{mmol}, 0.20$ equiv.) in dry THF $(10 \mathrm{~mL})$ was added a solution LDA (1.0 M in THF/hexanes, $2.0 \mathrm{~mL}, 2.00 \mathrm{mmol}, 2.00$ equiv) dropwise at $-78^{\circ} \mathrm{C}$ over $10 \mathrm{~min}$. Afterwards $n$-BuLi (1.6 M in hexanes, $2.1 \mathrm{~mL}, 3.30 \mathrm{mmol}$, 3.30 equiv) was added dropwise over $10 \mathrm{~min}$, followed by the dropwise addition of 2,3,5-triO-benzyl-D-ribono-1,4-lactone (2, 1.0 M in dry THF, $2.0 \mathrm{~mL}, 2.00 \mathrm{mmol}, 2.00$ equiv) over $5 \mathrm{~min}$. The reaction mixture was slowly warmed to $0{ }^{\circ} \mathrm{C}$, quenched with $\mathrm{NH}_{4} \mathrm{Cl}_{\mathrm{aq} .}(10 \mathrm{~mL})$ and subjected to HPLC analysis. The crude mixture contained $20 \%$ yield of the desired product 3 , using biphenyl as internal standard. 


\section{Calibration of HPLC}

The yield of the desired product 3 and side-product $\mathbf{1 - H}$ were calculated according to the calibration of both substances using biphenyl as internal standard (IS) for the HPLC method described above. For all calculations the HPLC peak area was monitored at wavelength $254 \mathrm{~nm}$ (Figure S1).

HPLC calibration of the desired product 3

a)

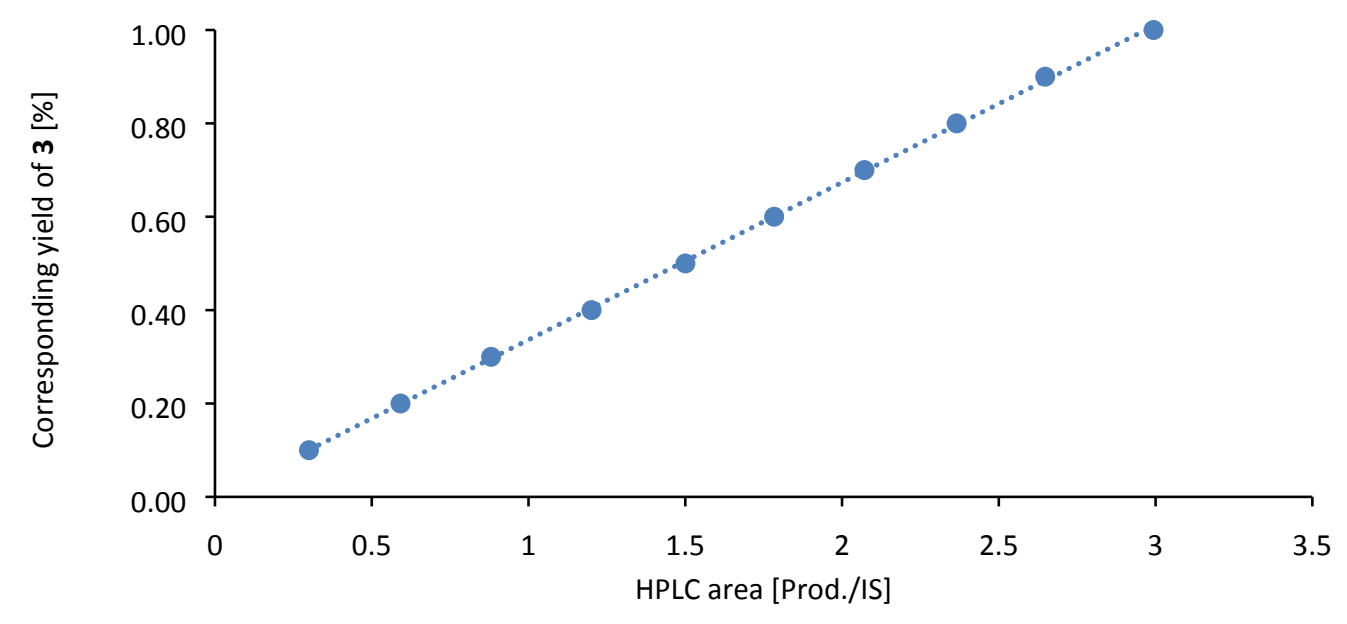

HPLC ealibration of side product 1-H

b)

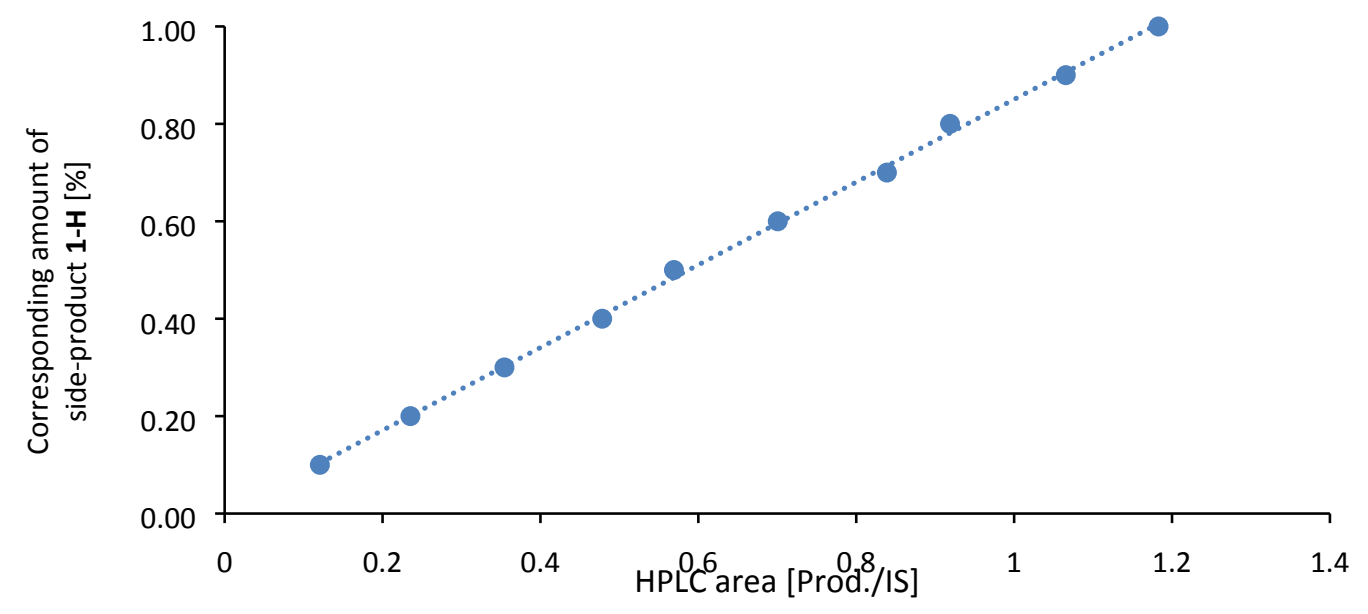

Figure S1. HPLC calibration for (a) the desired product $\mathbf{3}$ and (b) the side-product 1-H using biphenyl as internal standard respectively (monitored wavelength $254 \mathrm{~nm}$ ). 


\section{Reaction Optimization}

The optimization of the $C$-glycosylation step mainly concerns the improvement of the yield of the desired product $\mathbf{3}$ and the decrease of the side-products. Figure $\mathbf{S} 2$ shows an example HPLC chromatogram under non-optimized reaction conditions. The main side-products formed during the $C$-glycosylation process using organolithium species are the protonated heterocycle 1-H, silylated heterocycles 6, 7 and 8, and the elimination product $\mathbf{9 .}$

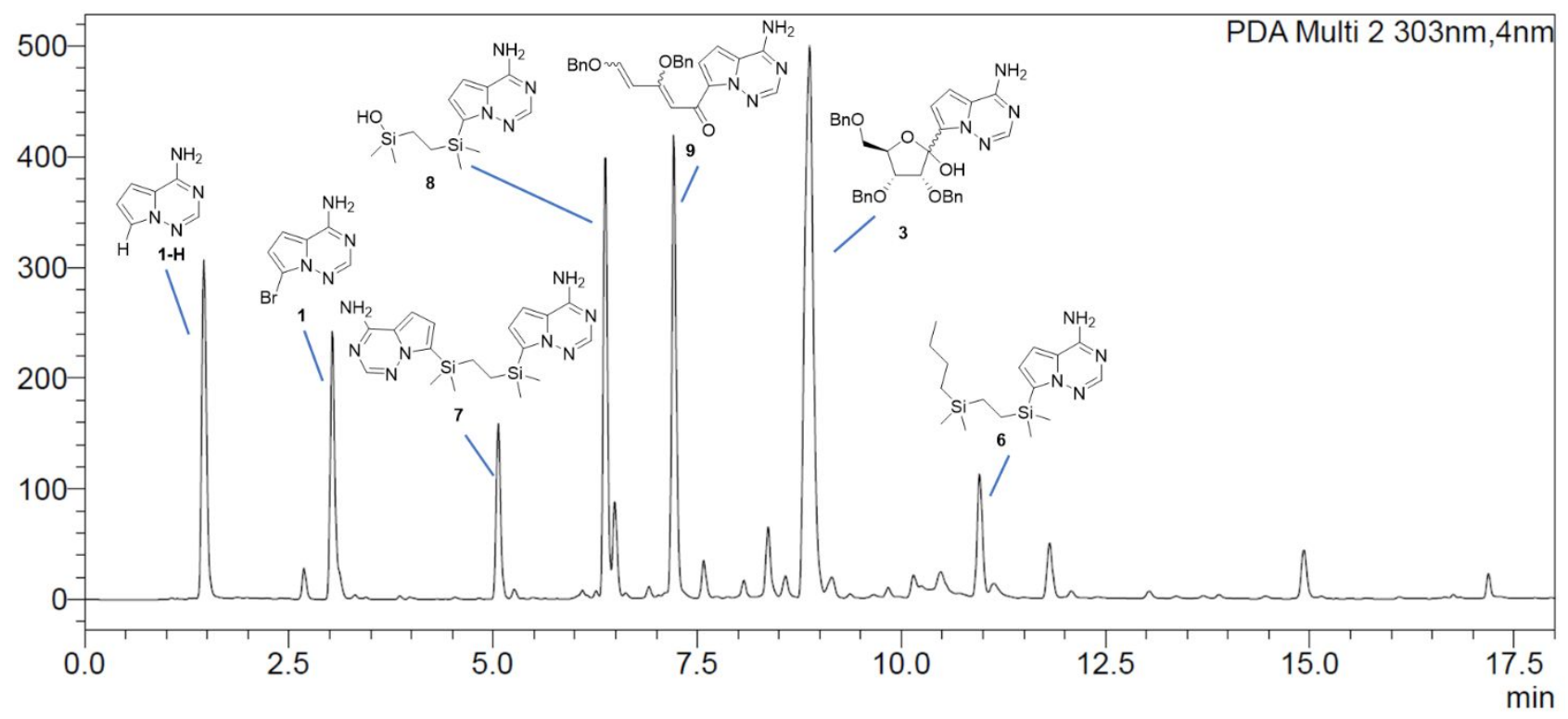

Figure S2. Example HPLC chromatogram of the $C$-glycosylation step under non-optimized reaction conditions.

The optimization reactions were performed under continuous flow conditions, utilizing an Ehrfeld FlowPlate (Hastelloy, TG-mixer, 1701-2643-HC) at $-30{ }^{\circ} \mathrm{C}$. The flow setup is described in detail in section 6 of the supporting information. 
To evaluate the effect of the bidentate protecting group BCDSE, a comparison versus trimethylsilyl chloride (TMSCl) was performed (Figure S3). For the comparison, the equivalents are based on the silyl-chloride moieties. This means that one equivalent of BCDSE counts as two equivalents of Si-Cl. It was found that BCDSE significantly improves the yield of the desired product 3 .

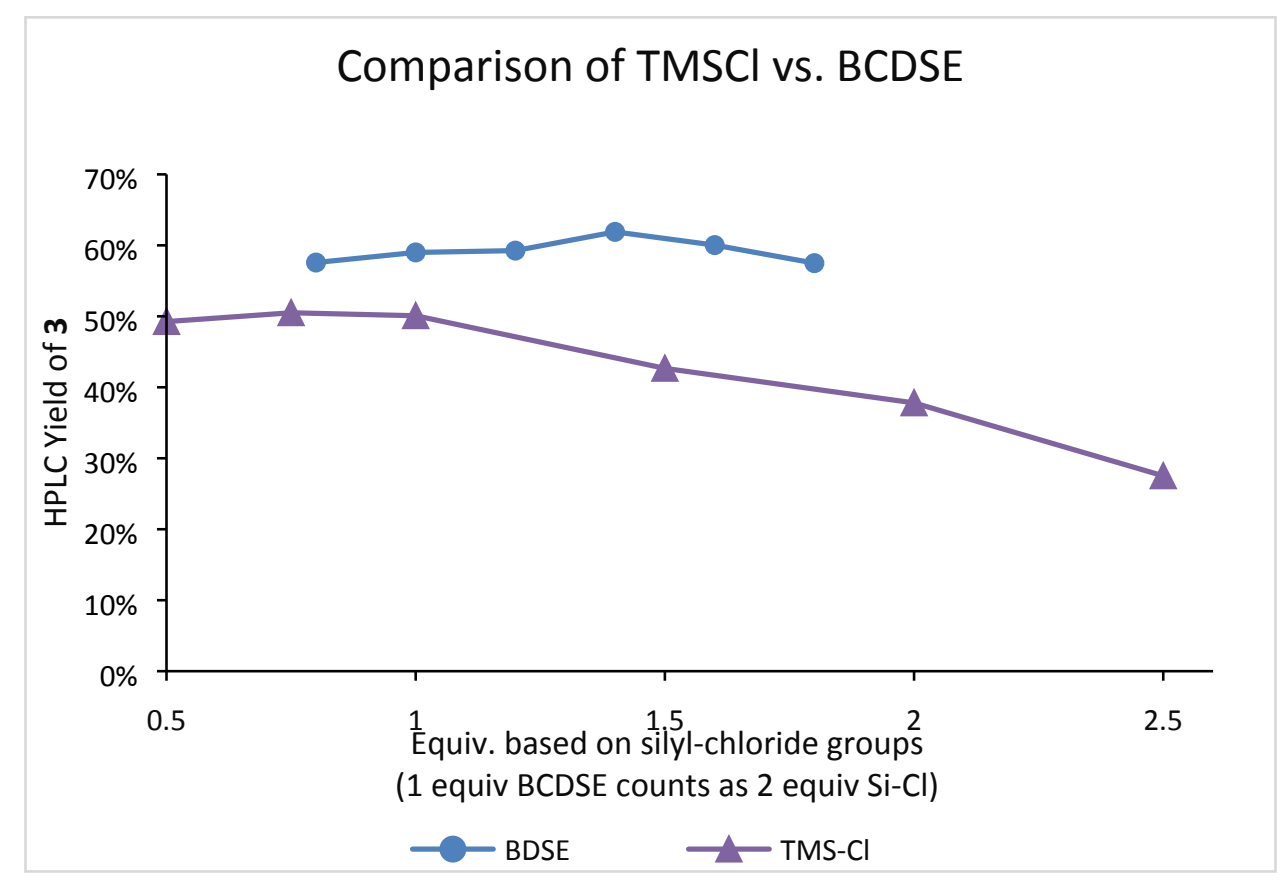

Figure S3. Evaluation of the performance of the monodentate TMS-Cl versus the bidentate BCDSE for the $C$-glycosylation process.

To find the optimal reaction conditions, the effect of $n$-BuLi equivalents on the reaction output was observed in the range of 2.00 to 3.20 equiv. by varying the flow rate of the $n$-BuLi feed (Figure S4). It was found, that using 2.50 equiv. of $n$-BuLi or less is insufficient and leads to an increase of the side-product 1-H. In the range of 2.90 to 3.20 equiv. increasing amount of $n$-BuLi leads to decrease of product 3. 


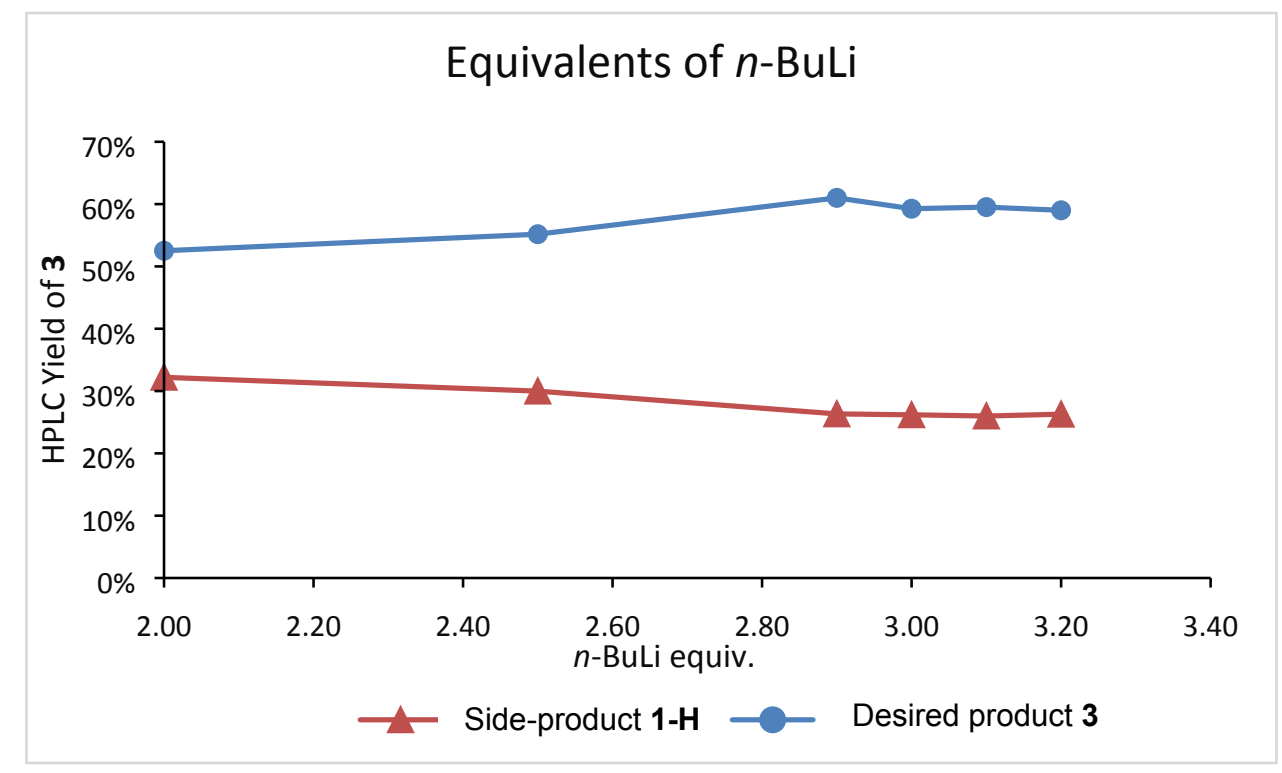

Figure S4. Screening of the equivalents of $n$-BuLi.

Eventually, the effect of the equivalents of ribonolactone $\mathbf{2}$ was evaluated by varying the flow rate. It was found, that using 1.80 equiv. of ribonolactone 2 is sufficient for the reaction. Using less than 1.80 equiv. results in an increased amount of side-product 1-H. Increasing the amount of $\mathbf{2}$ further to 2.00 equiv. did not improve the yield of the desired product 3 (Figure S5).

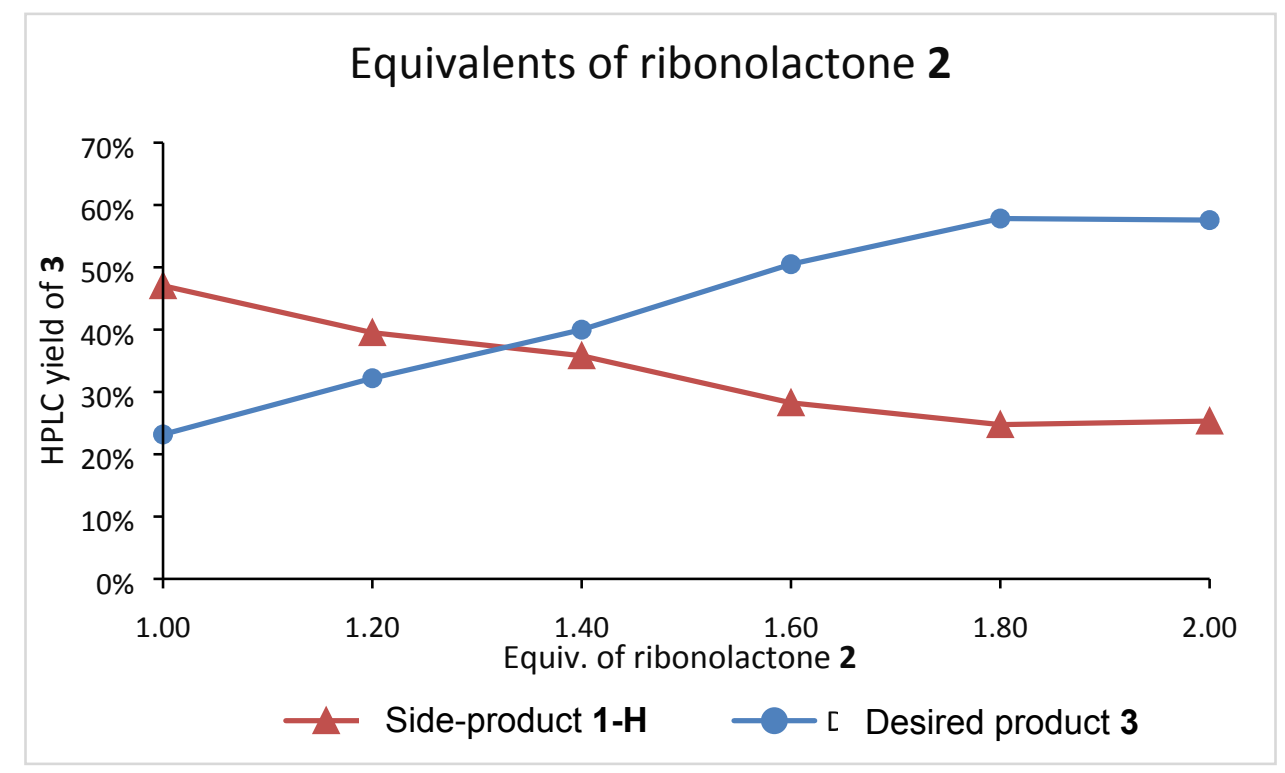

Figure S5. Screening of the equivalents of ribonolactone 2. 


\subsection{Continuous flow process in the absence of a silyl-protecting group}

The $C$-glycosylation process was performed in a continuous fashion in the absence of a silylprotecting group. The same setup, flow rates and temperatures as depicted in Figure S7 were applied. The flow process proofed to be unstable, as solids were formed almost instantaneously after the first injection of the organometallic species. However, three samples were taken at steady-state, with an average yield of $49 \%$ of the desired product 3 , according to HPLC analysis using biphenyl as internal standard. After a few minutes, the pressure increased significantly, eventually leading to blockage of the flow reactor.

\section{Continuous Flow Setup}

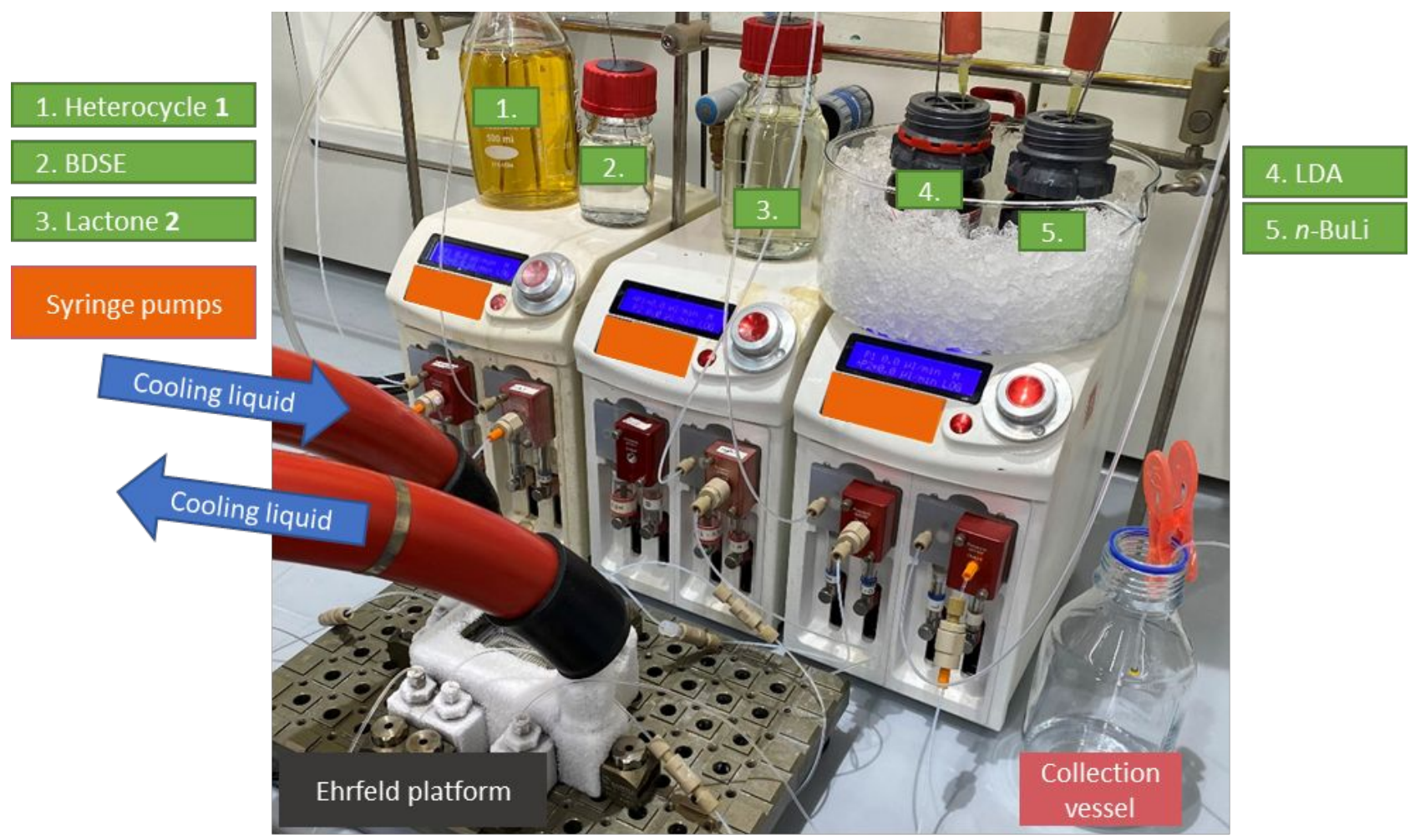

Figure S6. Flow setup utilized for continuous flow experiments.

The flow setup depicted in Figure $\mathbf{S 6}$ consists of three Syrris Asia syringe pumps, which are connected via PFA-tubs (0.8 mm ID) to the Ehrfeld platform. The Ehrfeld platform is equipped with an Ehrfeld FlowPlate (Hastelloy, TG-mixer, 1701-2643-HC), which is temperature controlled by a cryostat (Lauda Proline RP-890). If not stated otherwise, the following five stock solutions were prepared. 
1. 4-Amino-7-bromopyrrolo[2,l-f] $[1,2,4]$ triazine $(1,0.1 \mathrm{M}$ in dry THF) + biphenyl $(0.02 \mathrm{M})$ as internal standard

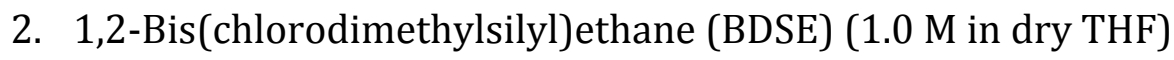

3. 2,3,5-Tri- $O$-benzyl-D-ribono-1,4-lactone (2,1.0 $\mathrm{M}$ in dry THF)

4. Lithium $N, N$-diisopropylamide (LDA) (1.0 M in hexane/THF) freshly prepared and stored at $0^{\circ} \mathrm{C}$

5. $n$-BuLi (1.6 M in hexanes) stored at $0{ }^{\circ} \mathrm{C}$

Stock solution for steam 4 (LDA) was prepared and titrated as follows:

A dry volumetric flask $(100 \mathrm{~mL})$ was charged with $N, N$-diisopropylamine $(14.1 \mathrm{~mL}$, $100 \mathrm{mmol}$ ) and dry THF (20 mL) under argon atmosphere. $n$-BuLi $(62.5 \mathrm{~mL}, 100 \mathrm{mmol}, 1.00$ equiv) was added dropwise at $-20^{\circ} \mathrm{C}$. After completion of the addition, desired volume was made up with dry THF to obtain a nominal LDA concentration of $1.0 \mathrm{M}$.

Titration was performed according to a literature procedure: ${ }^{3}$

To a solution of $N$-benzylbenzamide $(211 \mathrm{mg}, 1.00 \mathrm{mmol})$ in dry THF $(10 \mathrm{~mL})$ was added dropwise the organolithium reagent at $-20^{\circ} \mathrm{C}$. The endpoint of the titration was indicated by a persistent blue color.

Representative concentration results, using this procedure:

1.) $1.04 \mathrm{~mL}$ of LDA, corresponding to a $0.96 \mathrm{M}$ solution

2.) $1.03 \mathrm{~mL}$ of LDA, corresponding to a $0.97 \mathrm{M}$ solution

The five streams were connected to the FlowPlate as depicted in Figure S7. Bromopyrrolotriazinamine 1 was pre-mixed with BCDSE using inputs 1 and 2. After a TG-mixing zone $(14 \mu \mathrm{L})$ and an additional residence time zone $(87 \mu \mathrm{L})$, LDA was injected 
using input 3. This was followed by another residence time zone $(51 \mu \mathrm{L})$, before $n$-BuLi was injected using input 4 . After a second mixing zone (14 $\mu \mathrm{L})$ and another residence time zone $(65 \mu \mathrm{L})$, ribonolactone 2 was injected using input 5 . The reaction mixture was guided through another residence time zone $(124 \mu \mathrm{L})$, before leaving the FlowPlate using output 6. After passing through a PFA-tube $(460 \mu \mathrm{L})$ the mixture was quenched using $\mathrm{NH}_{4} \mathrm{Cl}_{\mathrm{aq}}$. 
a)

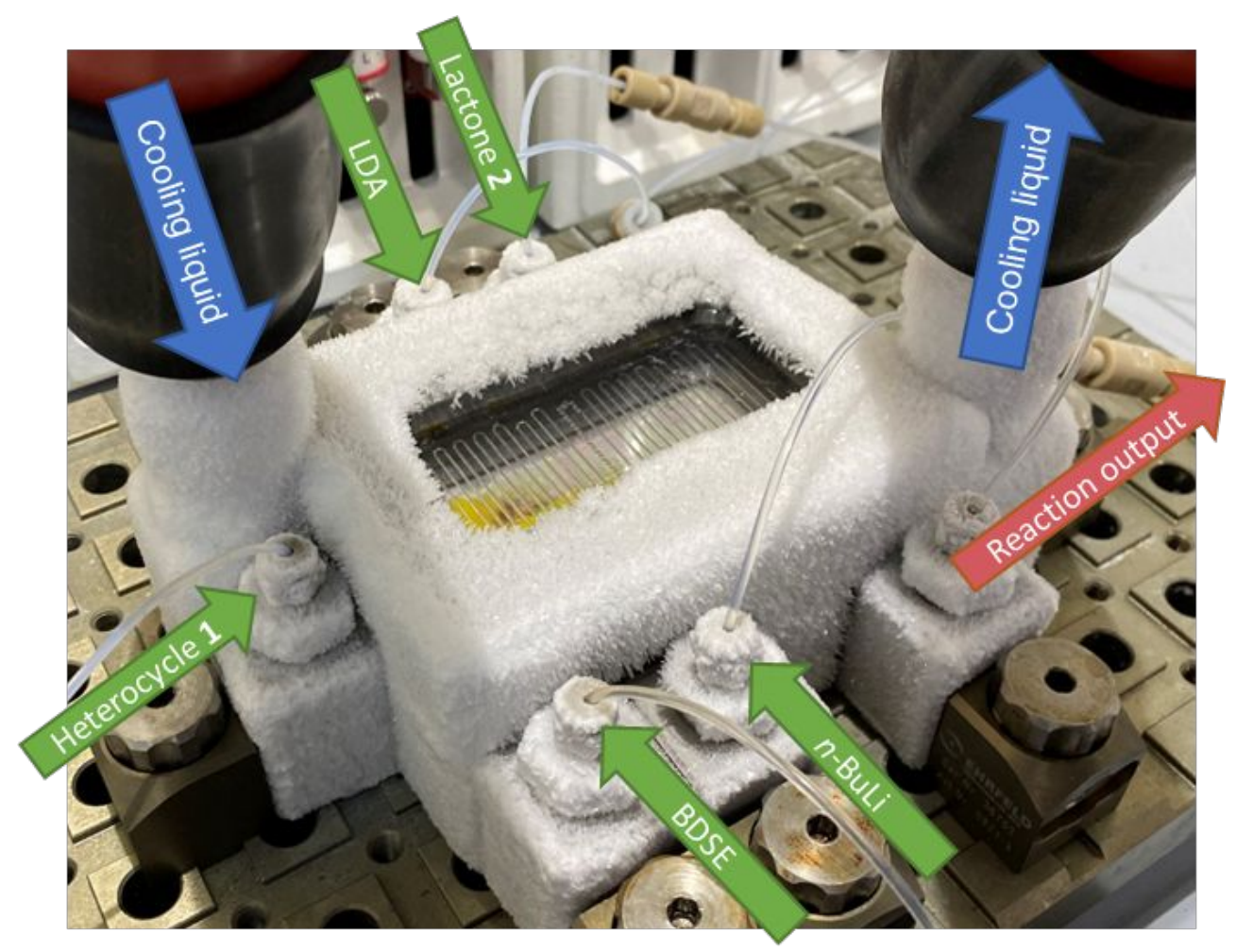

b)

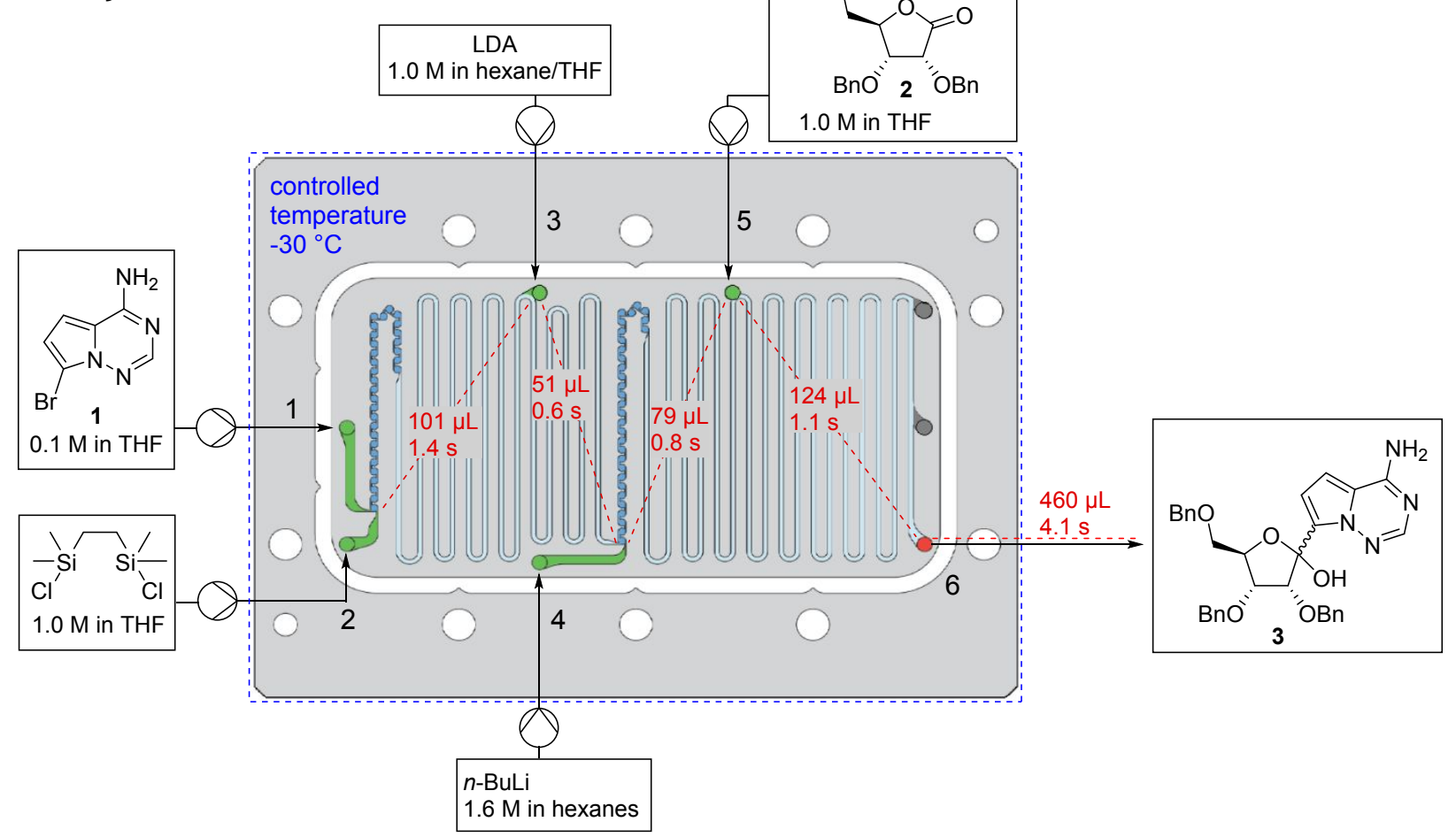

Figure S7. a) Picture of the Ehrfeld microreactor utilized for the continuous flow experiments. b) Schematic illustration of the Ehrfeld FlowPlate (TG-mixer, 1701-2643-HC). Flow rates, reaction volumes and residence times are calculated for the final setup utilized for the scale-out experiment. 
The continuous flow setup displayed in Figure S8 was utilized for experiments in Table 1, entry 4-5. The reaction inside the FlowPlate is similar to Figure S7. An additional residence time zone (capillary reactor, $4.0 \mathrm{~mL}$ ) was installed after FlowPlate output 6.

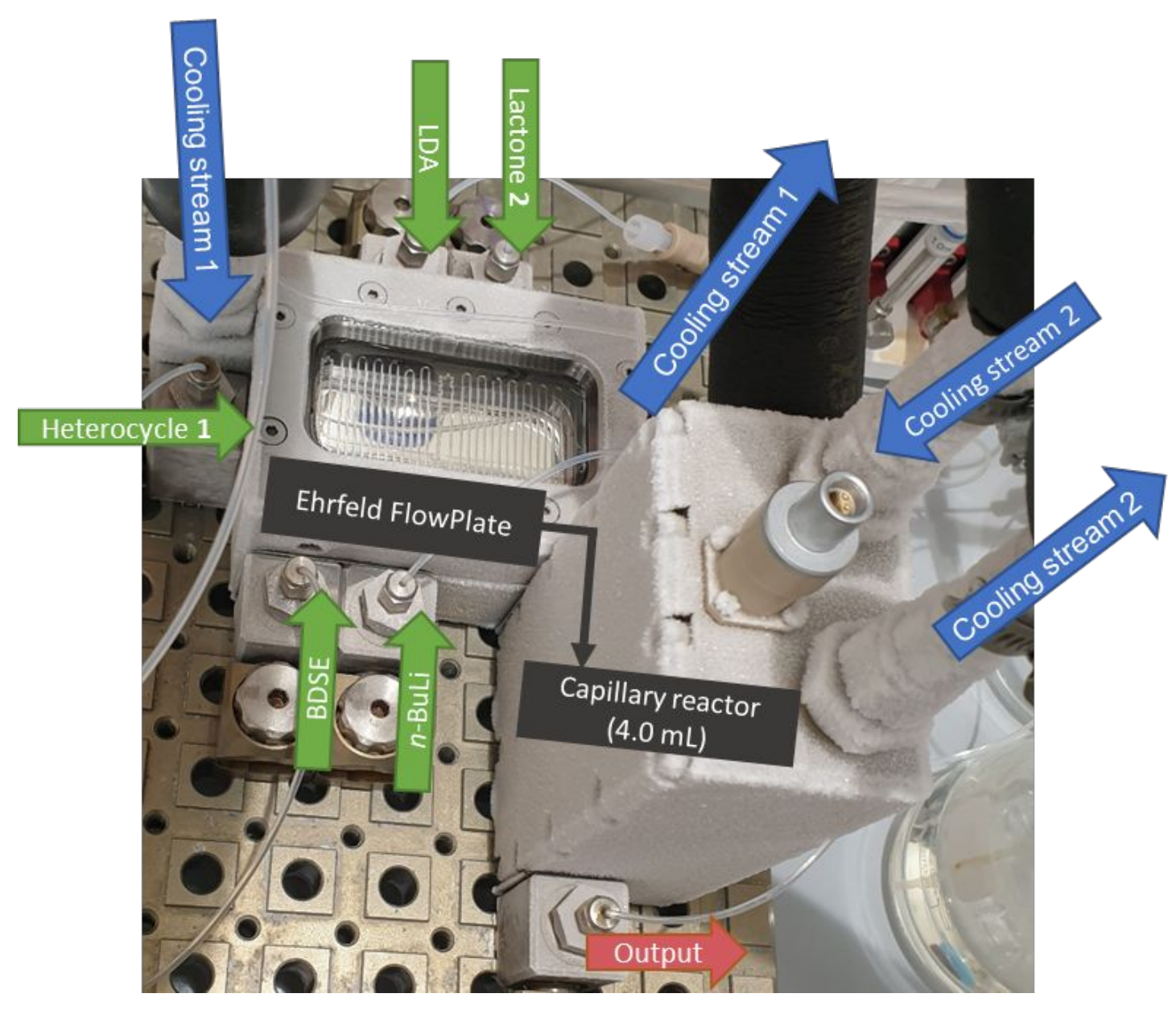

Figure S8. Flow setup with additional residence time unit (capillary reactor, $4.0 \mathrm{~mL}$ ) connected to the Ehrfeld FlowPlate. This setup was utilized for reaction described in Manuscript Table 1, entry 45 . 


\section{Long run Experiment}

To evaluate the robustness and consistency of the developed continuous flow process, a long run experiment over $2 \mathrm{~h}$ was conducted. For this experiment the setup depicted in Figure $\mathbf{S 9}$ was utilized. All five utilized streams were connected to the FlowPlate.

Bromopyrrolotriazinamine 1 ( $0.1 \mathrm{M}$ in dry THF, $4.11 \mathrm{~mL} / \mathrm{min}, 1.00$ equiv.) was pre-mixed with BCDSE (1.0 M in dry THF, $0.247 \mathrm{~mL} / \mathrm{min}, 0.60$ equiv.) using inputs 1 and 2 . After a first residence time zone $(14 \mu \mathrm{L}+87 \mu \mathrm{L}, 1.4 \mathrm{~s})$, LDA $(1.0 \mathrm{M}$ in THF/hexane, $0.822 \mathrm{~mL} / \mathrm{min}$, 2.00 equiv.) was injected using input 3 . This was followed by another residence time zone (51 $\mu \mathrm{L}, 0.6 \mathrm{~s})$, before $n$-BuLi $(1.6 \mathrm{M}$ in hexanes, $0.711 \mathrm{~mL} / \mathrm{min}, 3.00$ equiv.) was injected using input 4 . After a second mixing zone and another residence time zone $(14 \mu \mathrm{L}+65 \mu \mathrm{L}$, $0.8 \mathrm{~s})$, ribonolactone $2(1.0 \mathrm{M}$ in dry THF, $0.740 \mathrm{~mL} / \mathrm{min}, 1.80$ equiv.) was injected using input 5. The reaction mixture was guided through another residence time zone at $-30{ }^{\circ} \mathrm{C}$ (124 $\mu \mathrm{L}, 1.1 \mathrm{~s}$ ), before leaving the FlowPlate using output 6. After passing through a PFAtube ( $460 \mu \mathrm{L}, 4.1 \mathrm{~s}$ ) the mixture was quenched using $\mathrm{NH}_{4} \mathrm{Cl}_{\mathrm{aq}}$. 


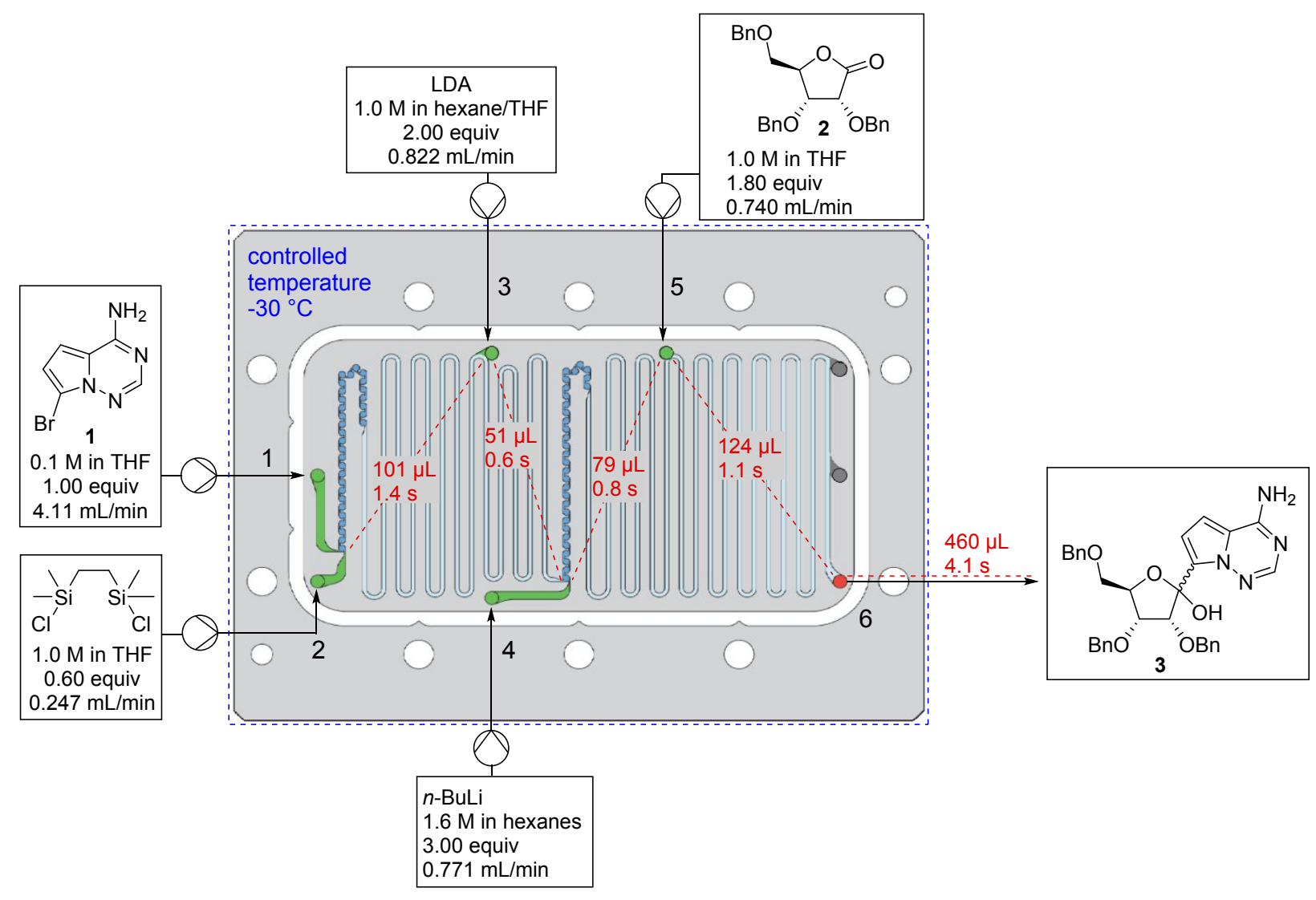

Figure S9. Schematic layout of the Ehrfeld FlowPlate (TG-mixer) utilized for the long run experiment.

The reaction output was collected in 24 fractions, each for 5 min, quenched with $\mathrm{NH}_{4} \mathrm{Cl}_{\mathrm{aq}}$. $(10 \mathrm{~mL})$ and analyzed by HPLC (Figure S10). The fractions were combined and extracted with $\mathrm{Et}_{2} \mathrm{O}(3 \times 300 \mathrm{~mL})$. The combined organic layers were dried over $\mathrm{Na}_{2} \mathrm{SO}_{4}$ and the volatiles were removed under reduced pressure. The crude product was purified by flash column chromatography (gradient 10\% $\rightarrow$ 100\% EtOAc in petrol ether). In total $49.0 \mathrm{mmol}$ of the starting material 1 were processed, yielding 16.9 g (60\% yield, 29.4 mmol, when taking into account $96 \%$ purity) of the desired product 3 as pale yellow foam. 


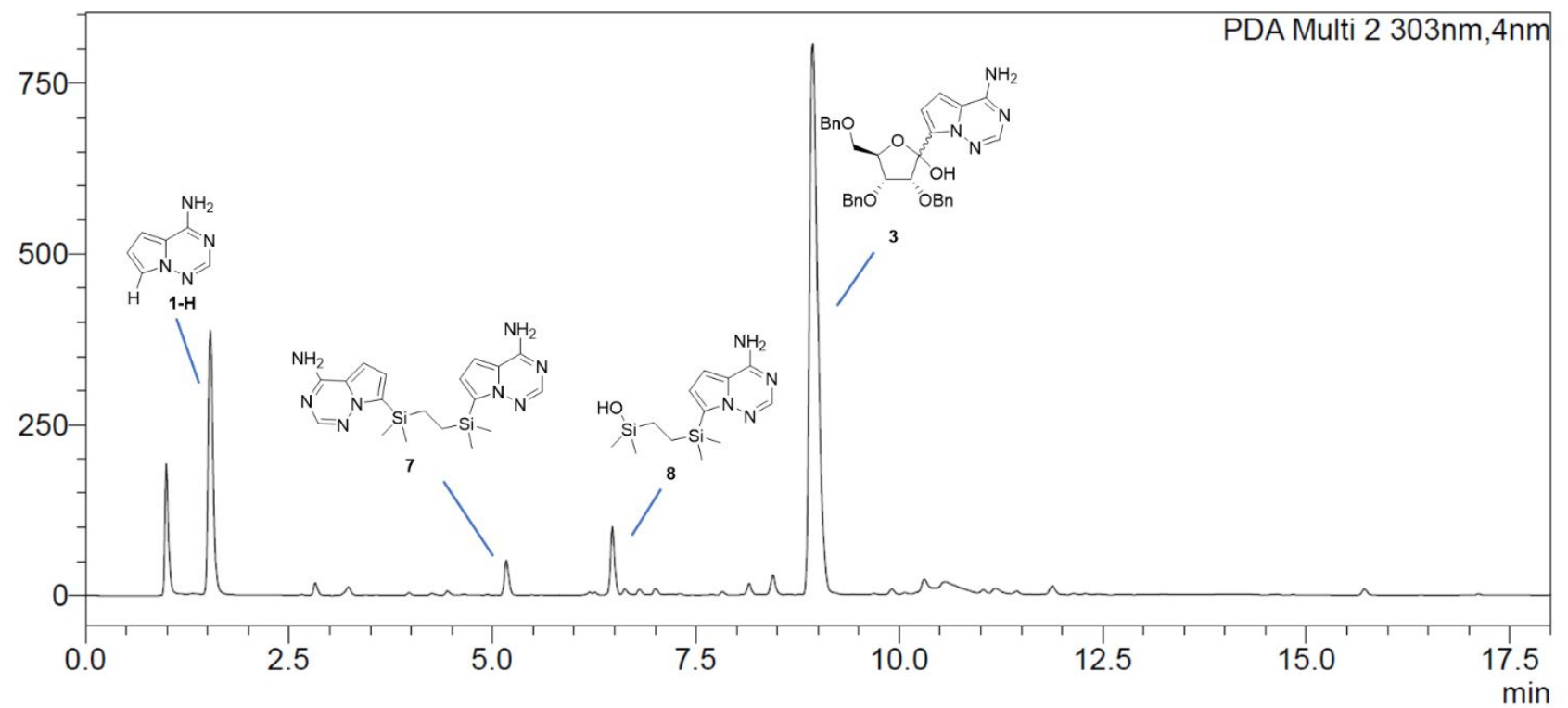

Figure S10. Example HPLC chromatogram of the long run (sample 24). The main side-products are the protonated heterocycle $\mathbf{1}-\mathbf{H}$ and the silylated heterocycles $\mathbf{7}$ and $\mathbf{8}$. 


\section{References}

(1) Hill, M. D.; Fang, H.; King, H. D.; Iwuagwu, C. I.; McDonald, I. M.; Cook, J.; Zusi, F. C.; Mate, R. A.; Knox, R. J.; Post-Munson, D.; et al. Development of 4-Heteroarylamino-1'-Azaspiro[oxazole5,3'-bicyclo[2.2.2]octanes] as $\alpha 7$ Nicotinic Receptor Agonists. ACS Med. Chem. Lett. 2017, 8, 133-137.

(2) Xue, F.; Zhou, X.; Zhou, R.; Zhou, X.; Xiao, D.; Gu, E.; Guo, X.; Xiang, J.; Wang, K.; Yang, L.; Zhong, W.; Qin, Y. Improvement of the C-Glycosylation Step for the Synthesis of Remdesivir. Org. Process Res. Dev. 2020, 24, 1772-1777.

(3) Burchat, A. F.; Chong, J. M.; Nielsen, N. Titration of Alkyllithiums with a Simple Reagent to a Blue Endpoint. J. Organomet. Chem. 1997, 542, 281-283. 
9. NMR Spectra

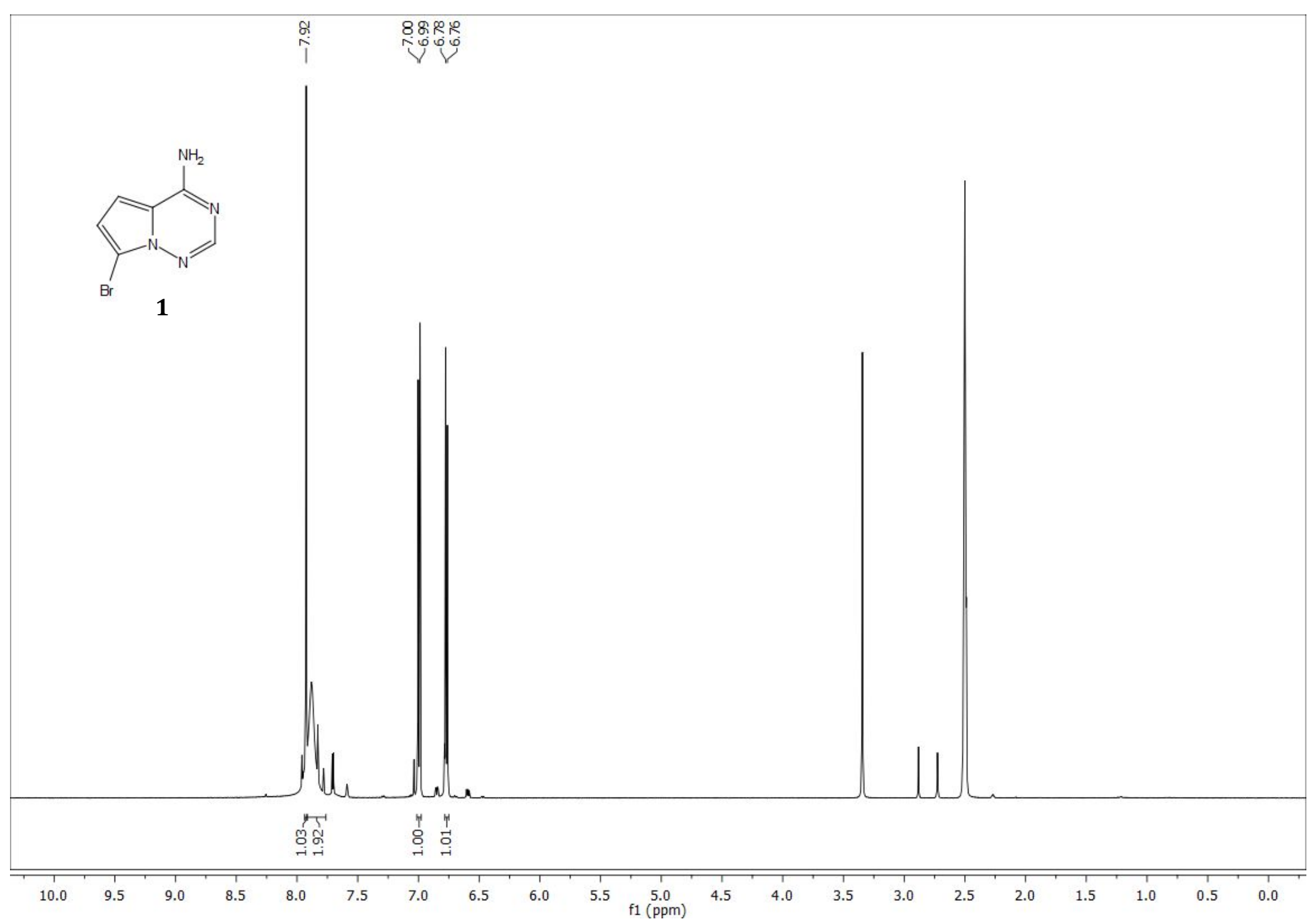




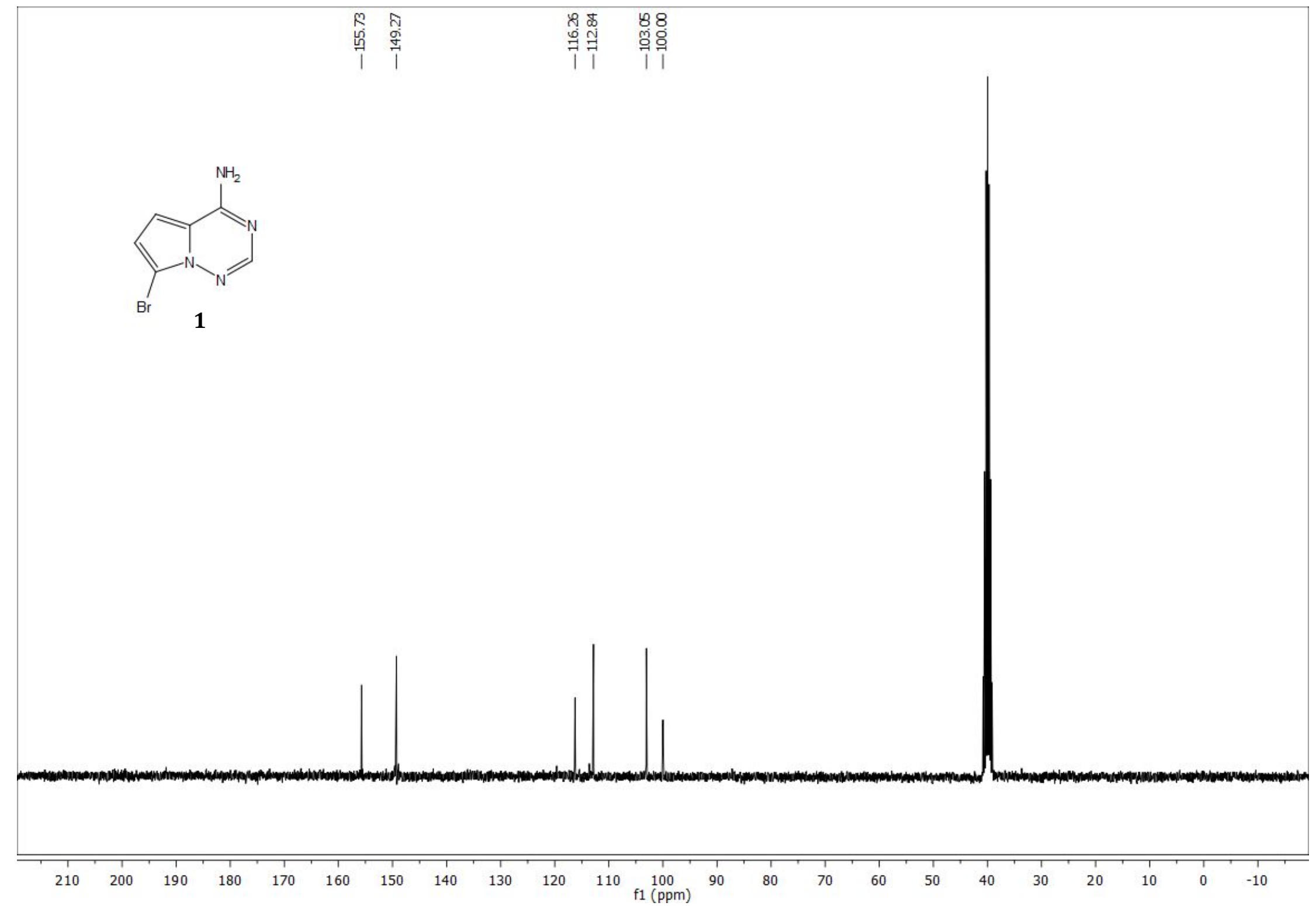




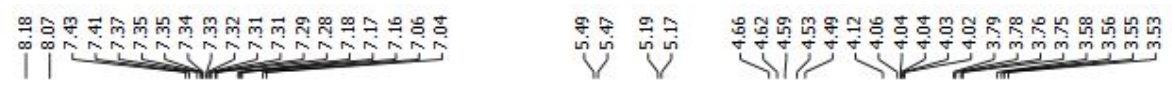

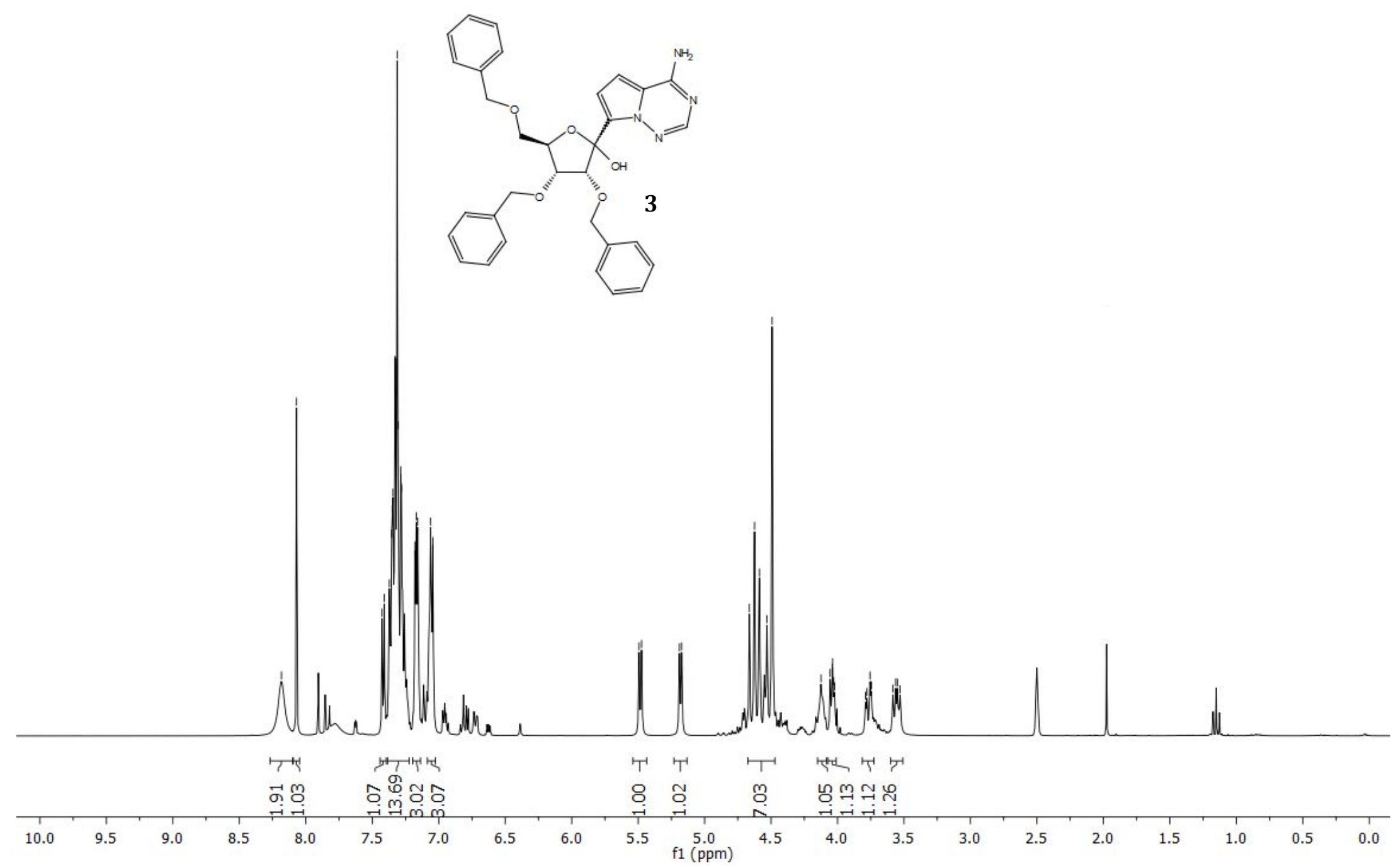




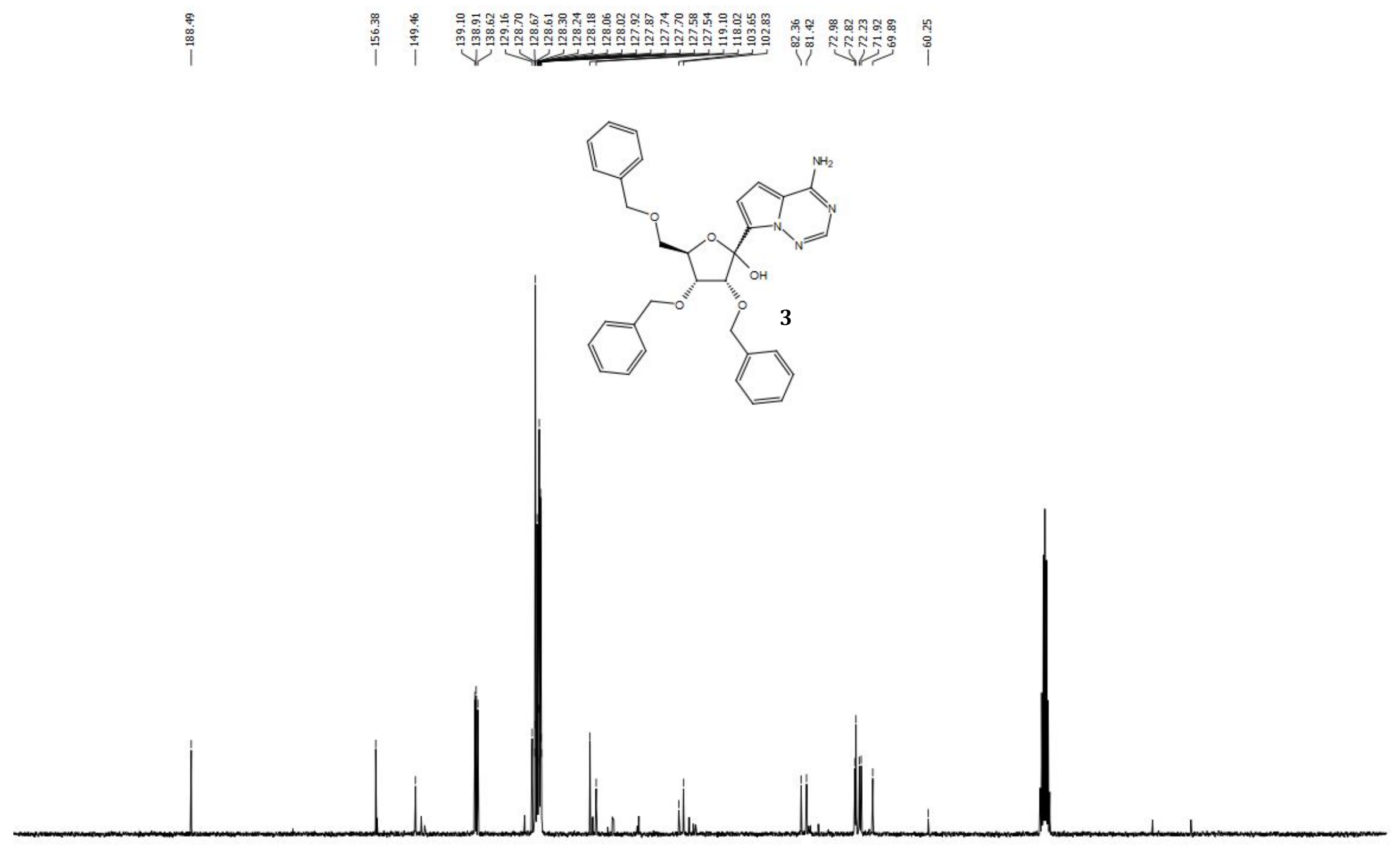

$\begin{array}{llllllllllll}210 & 200 & 190 & 180 & 170 & 160 & 150 & 140 & 130 & 120 & 110 & 100 \\ \mathrm{f} 1(\mathrm{ppm})\end{array}$

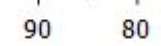

